\title{
THE TREATMENT OF AGRANULOCYTOSIS WITH ADENINE SULPHATE 1,2
}

\author{
BY PAUL REZNIKOFF
}

(From the Department of Medicine, Cornell University Medical College and the Second Medical (Cornell) Division, Bellevue Hospital, New York City)

(Received for publication August 2, 1932)

On December 20, 1928, a young physician suffering from agranulocytosis was given the salt of a purine base, adenine sulphate, intravenously and recovered promptly (1). This, as far as can be ascertained, was the first time such a substance had been tried for this condition. Its use was prompted by the fact that previous animal experimentation suggested that purine salts, and some of the substances from which purines are derived, seemed effective in increasing granulocytes in the peripheral blood stream (2) (3) (4). Since the first report (1) of its use, adenine sulphate has been given by us, or its administration reported to us in 35 cases.

Of these patients, 15 were definitely diagnosed as having had "primary" agranulocytosis, showing a marked diminution of granulocytes with or without inflammation of the pharynx; 8 showed agranulocytosis, either characterized by serious complications or occuring in the course of some other illness; and 12 individuals had some definite condition other than agranulocytosis and the depression of granulocytes was either incidental or occurred as part of the general picture.

Most of these patients were treated rather cautiously with what was at first considered adequate dosage. With more experience, especially with respect to the relative non-toxicity of the adenine salt, we now use as the present dosage for an adult $1 \mathrm{gram}$ boiled in 35 or $40 \mathrm{cc}$. of physiological saline, administered intravenously, sufficiently warm to prevent precipitation, 3 times a day for at least three days. Even this is probably not a maximum dose, but in most patients who responded favorably it was found that with such quantities distinct improvement occurred in symptoms, in decline of fever and in increase of granulocytes within $\mathbf{4 8}$ hours, frequently within 24 hours. As much as 10.4 grams have been given to a patient within 7 days with no ill effects. It is necessary to emphasize this question of dosage to arrive at a proper evaluation of the results to be reported.

1 Acknowledgment is made to the physicians whose names appear in the tables, and who permitted us to use the results which are given in this study.

2 Adenine sulphate has been obtained from the Eastman Kodak Company of Rochester, New York. 
Table I summarizes the results obtained with a group of 15 patients who suffered from what might be termed agranulocytosis "vera," because they showed the classical signs and symptoms of this condition.

The results obtained in treating this group give a total recovery rate of 73 per cent which is about the same as that obtained by Jackson (5) with the more complex nucleotide. A more detailed analysis of these cases shows that of the four patients who did not recover, three died within 15 hours after the administration of adenine sulphate was begun; and the fourth within two days. This last patient was given a transfusion and, what is even more significant with respect to a depressing effect on the bone marrow, neosalvarsan intravenously. One of these fatal cases received a transfusion of $900 \mathrm{cc}$. of blood and salvarsan. In two of these fatal cases only 1 dose of 0.5 gram of adenine sulphate was given; in one, 2 doses of $0.5 \mathrm{gram}$; and in one, 3 doses of $0.8 \mathrm{gram}$. It should also be pointed out that three of the patients who recovered showed improvement as far as appearance of granulocytes was concerned, before adenine sulphate was administered. This is a very significant observation because in evaluating adenine sulphate therapy it is essential to keep constantly in mind the possibility of spontaneous recovery. Of the patients who recovered, almost all showed evidence of response to adenine sulphate within 24 hours after the administration of the purine salt, as evidenced by the beginning increase in granulocytes, drop of temperature and symptomatic improvement; and most of the patients demonstrated very distinct improvement within 48 hours. This quick reaction is important, of course, because of the acuteness of the disease. It is not the purpose of this paper to analyze the individual cases, except as is necessary to follow the therapy, but attention should be called to the low initial total and polymorphonuclear counts of most of the recovered patients.

The second group of 8 cases (Table II), includes patients in whom the diagnosis of agranulocytosis was questionable, or in whom what might have been either the primary disease or serious complications of agranulocytosis dominated the picture. The disease did not represent a clear cut clinical entity, and all that can be definitely stated is that a blood picture of agranulocytosis was present. The possibility must, of course, be considered that this group of cases represents a late stage of the typical agranulocytic condition from which the patients have not recovered quickly, either as a result of therapy or spontaneously. Only one patient of this type recovered after adenine sulphate therapy. In this group, therefore, the recovery rate was one out of eight. An analysis of Table II shows that 3 patients had marked anemia, two had marked lymphadenitis, one suffered from multiple bone marrow abscesses of pneumococcus origin and septicemia, two had cardiac failure, one had pulmonary edema, in one there was a question as to whether the diagnosis 


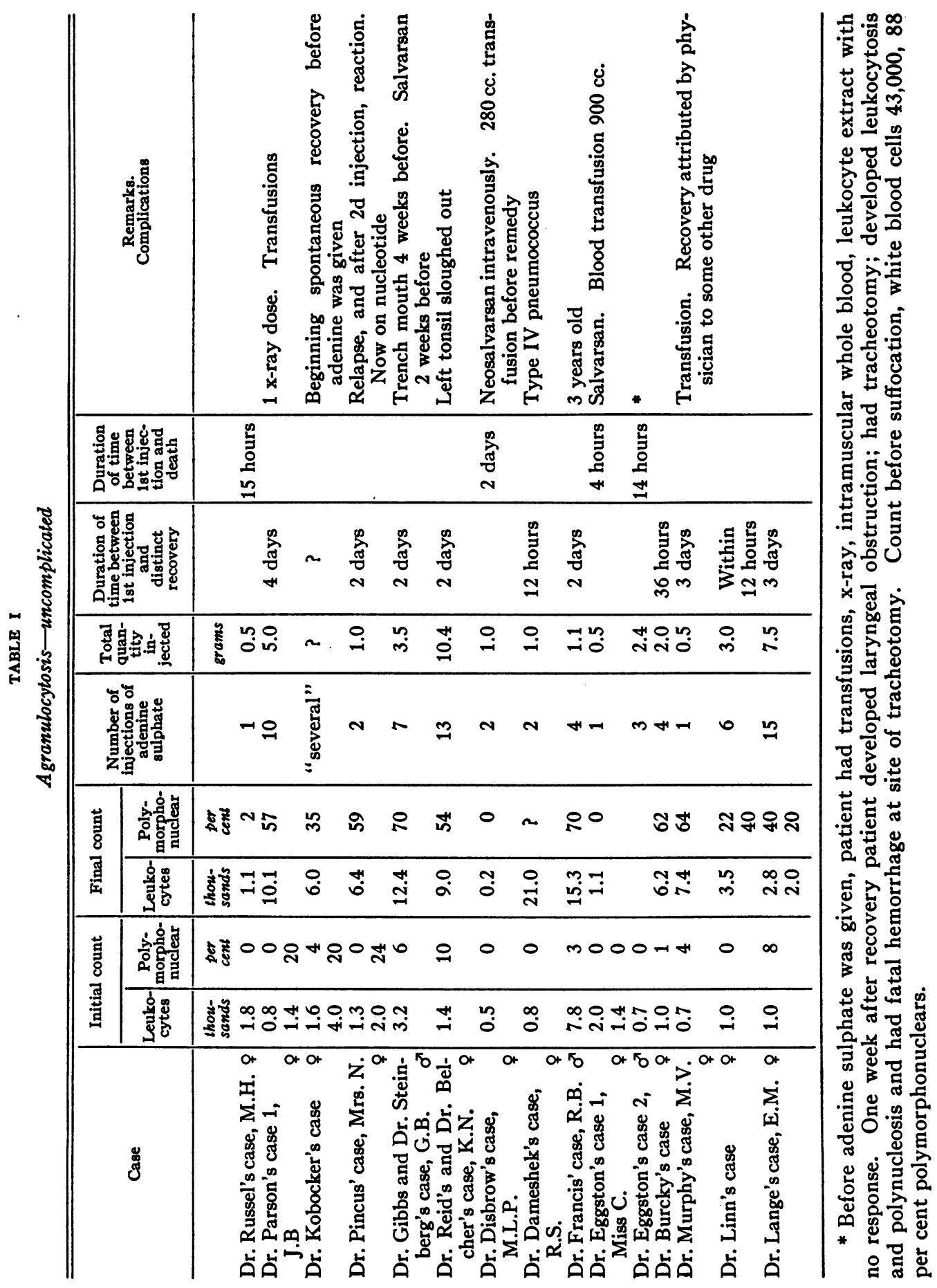




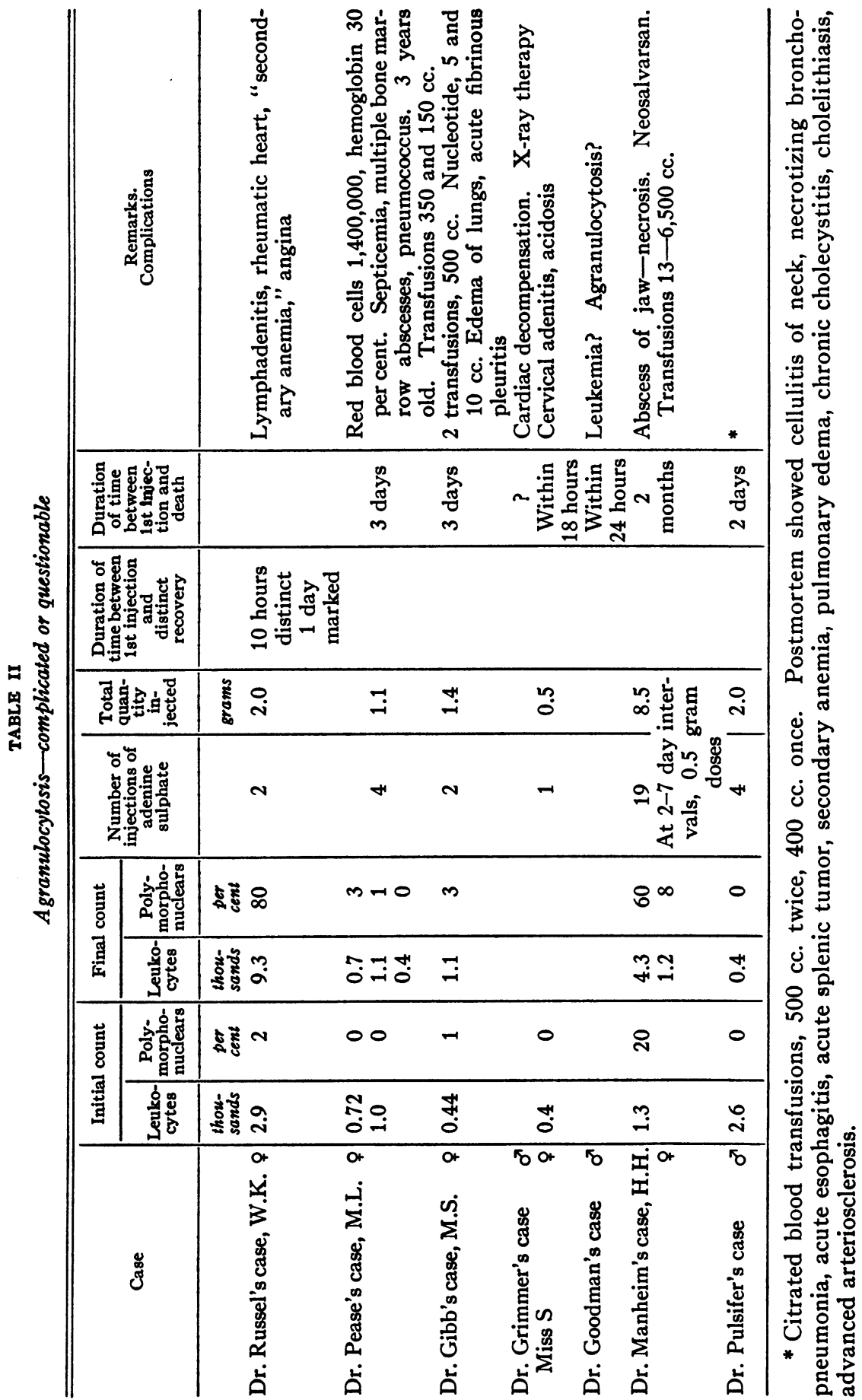


was not really aleukemic leukemia, one had necrosis of the jaw, and one patient showed cellulitis of the neck, necrotizing bronchopneumonia, and chronic cholecystitis and cholelithiasis. In addition to adenine sulphate 4 of these patients received transfusions; one, $x$-ray therapy; and one nucleotide. Of the patients who died only one received more than 2.0 grams of adenine sulphate. This patient (H. H.) had a total of 8.5 grams given to her over a period of two months, and at one time her count rose to 4,300 leukocytes with 60 per cent polymorphonuclear cells.

Table III presents the results obtained with adenine sulphate in 12 patients who suffered from some disease other than agranulocytosis but in whom agranulocytosis developed during the course of illness or was a concomitant finding. Of these, 3 patients suffered from aleukemic leukemia; 5 from lues and anti-luetic (arsenicals) therapy; 1 from a mastoid infection; 1 from carcinoma of the prostate; 1 from generalized abdominal carcinomatosis, for which she had received radiation therapy; and 1 from staphylococcus septicemia. Aleukemic leukemia was included in this group for the following three reasons: (a) because of a report of a possibly successful outcome with nucleotide $(6) ;(b)$ because in some of these cases agranulocytosis was diagnosed and treatment commenced before the true condition was apparent; and $(c)$ because in a strict sense this condition is certainly accompanied by some degree of granulocytopenia. The cases of arsphenamine poisoning really should be classified as aplastic anemia or probably acute myelophthisis since all blood elements are involved. Here again agranulocytosis is part of the picture. This problem of classification has been thoroughly discussed by Rosenthal (7) and by Roberts and Kracke (8). In this series the recovery rate with adenine sulphate therapy was one out of twelve. The patient who recovered was a child who subsequently had a relapse after his operation for mastoiditis. After a single dose of $0.3 \mathrm{gram}$ of adenine sulphate and transfusions, the child's count rose from 1,400 leukocytes and 6 per cent polymorphonuclears to 6,900 leukocytes and 60 per cent polymorphonuclears. Adenine sulphate was not administered during the relapse, and he was treated only by transfusions. After the relapse the patient's count varied from 1,200 leukocytes to 1,000 leukocytes and showed 0 per cent polymorphonuclears despite frequent transfusions. The patient suffering from staphylococcus septicemia had a rise of leukocytes from 2,000 to 29,600 and of polymorphonuclears from 2 to 94 per cent in 6 days but died 4 days later. The patients suffering from aplastic anemia following arsphenamine therapy and those suffering from aleukemic leukemia showed no change in blood count following the administration of adenine sulphate. 


\begin{tabular}{|c|c|c|c|c|c|c|c|c|c|c|c|c|}
\hline & 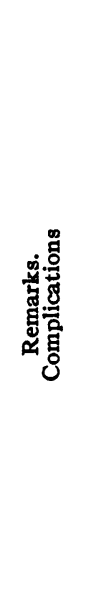 & 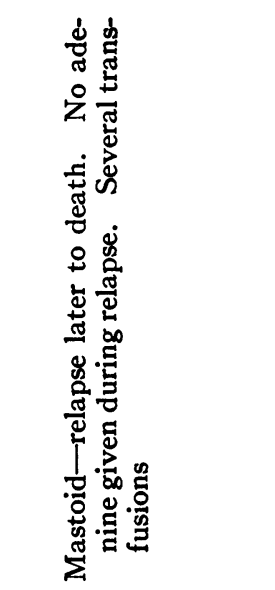 & & 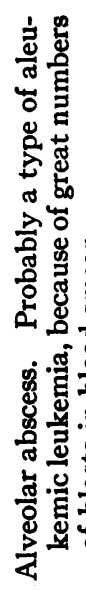 & 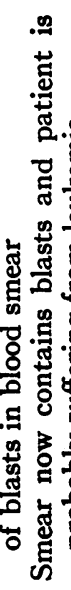 & 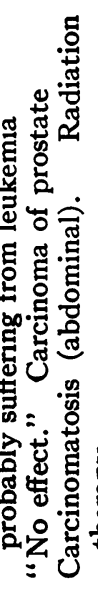 & 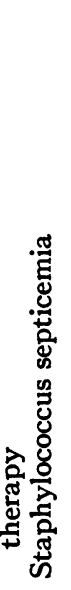 & 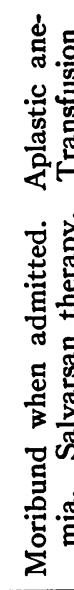 & & 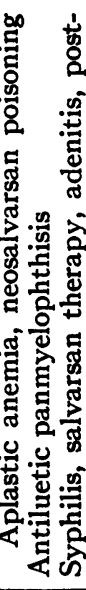 & 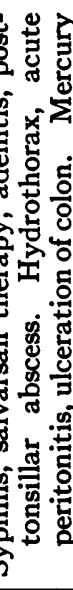 & 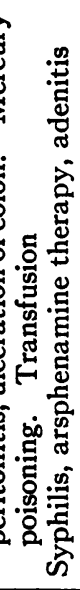 \\
\hline : & 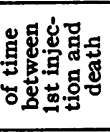 & 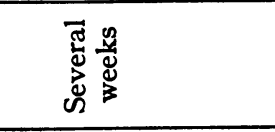 & 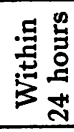 & $\begin{array}{l}2 \\
\frac{\pi}{2} \\
\frac{0}{2}\end{array}$ & 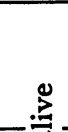 & 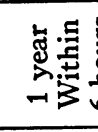 & $\begin{array}{l}0 \\
\stackrel{2}{3} \\
0 \\
0 \\
0 \\
0 \\
0\end{array}$ & $\begin{array}{l}\frac{\pi}{d} \\
\frac{\pi}{2} \\
N\end{array}$ & n & 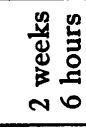 & & 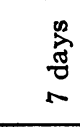 \\
\hline 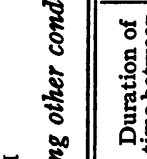 & 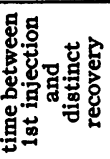 & 蛋 & & & 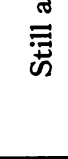 & & & & & & & \\
\hline (ई & 这 & $\begin{array}{ll}0 \\
E \\
E\end{array}$ & & $\stackrel{\infty}{+}$ & $\stackrel{9}{+}$ & $\ddot{n}$ & $\stackrel{\circ}{\circ}$ & $\stackrel{n}{\sim}$ & & 웅ํㅇ & & $\underset{\infty}{0}$ \\
\hline 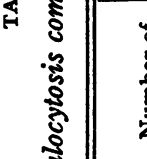 & 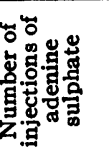 & $\rightarrow$ & & in & $N$ & -1 & 0 & $m$ & & $\stackrel{\infty}{\sim}-1$ & & 욱 \\
\hline 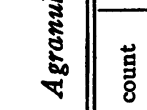 & | & 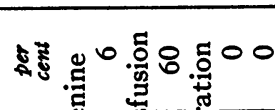 & & নิ & ా్ల & & ప゙ & న్ర & & & & $\infty$ \\
\hline 丞 & 今ं & 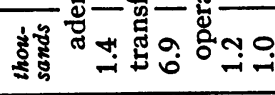 & & $\stackrel{m}{i}$ & $\overrightarrow{0}$ & & ลุ. & E พั & & ֻั? & & $\stackrel{H}{i}$ \\
\hline 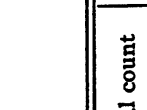 & 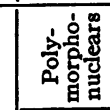 & \& & & $a$ & $\simeq$ & 0 & $N$ & $\ddot{N}$ & & 으 & ? & + \\
\hline 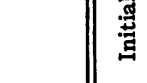 & 㝘嵒 & 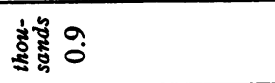 & & $\stackrel{a}{i}$ & $\stackrel{0}{+}$ & ஸุ & $\stackrel{\circ}{i}$ & $\hat{0}$ & & ثัฒ & & $\stackrel{\infty}{0}$ \\
\hline & ש̋ & 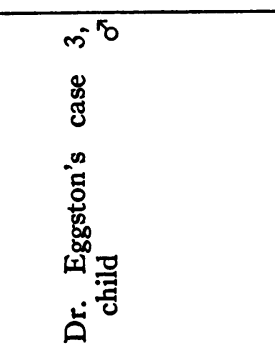 & 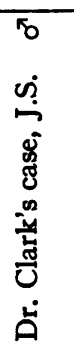 & نَ & 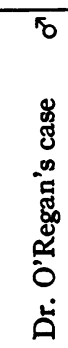 & 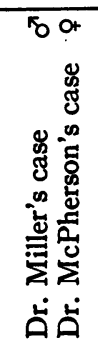 & 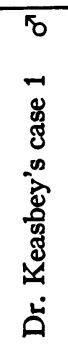 & 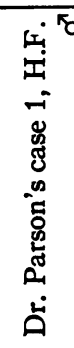 & 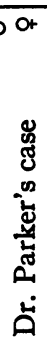 & 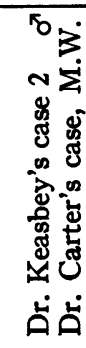 & & 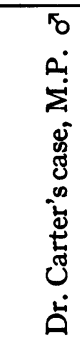 \\
\hline
\end{tabular}


DISCUSSION

The subject of agranulocytosis has been reviewed so often recently that it would be superfluous in this limited study on therapy to discuss the condition in detail. It should be pointed out that probably the first case to be described was that by an American, Brown (9) in 1902. Schwarz in 1904 (10) and Türk (11) in 1907 published case reports, and in 1922 Schultz (12) first described the syndrome of agranulocytosis in some detail. However, there is justifiable doubt concerning the advisability of classifying this condition as a clinical entity. Hartwich (13) has summarized the evidence recently and his conclusion that agranulocytosis is a symptom complex which mirrors a constitutional inferiority of the bone marrow seems to be the most acceptable viewpoint at present.

Aside from the symptomatic treatment, the chief methods of therapy tried in any considerable number of cases of agranulocytosis are, $(a)$ radiation, $(b)$ transfusions and $(c)$ purine or nucleotide therapy. These latter chemicals are grouped together because in all probability the active principle in them is the same. The chief exponents of radiation therapy are Friedemann and Elkeles (14). Taussig and Schnoebelen (15) and Gager and Speer (16) also reported a small number of cases. In 1928 Friedemann (17) reported that 6 of 10 patients, 60 per cent, treated by x-ray recovered. In 1930, Friedemann and Elkeles (14) reported a total of 43 cases with recovery of 13,30 per cent. However, they point out that 23 of these patients had sepsis or pneumonia. Therefore, $\mathrm{x}$-ray therapy has been followed, in uncomplicated cases, by a recovery rate of 65 per cent. If the further deduction of 5 is made for the patients who died within 36 hours after onset of treatment, the recovery rate with radiation is raised to 87 per cent. Even if such deductions are permissible, the chief cautions to be observed, in evaluating this method of therapy, are the time element that must elapse in these very acute cases before the supposed effect of radiation is manifested, and the absence of proof that radiation actually stimulates granulocytopoiesis. If radiation stimulates the granulocytic elements of the bone marrow by contiguous hyperemia or fixed tissue cell proliferation, subsequent atrophy of the granulocytes may result. That this is not entirely a theoretical objection, is suggested by a study of two of the cases reported by Taussig and Schnoebelen (15). The patients had an acute relapse after recovery from an attack in which radiation was used as a therapeutic measure. Radiation was completely ineffective in the relapse.

Transfusions are given constantly in agranulocytosis although no extensive series of cases, treated by this method, has been reported. As far as is known, transfusions or intramuscular injections of blood have never been shown to stimulate the production of polymorphonuclear leukocytes. Hartwich (13) advocates its use solely for its effect on temperature. Our experience suggests that a large transfusion may 
actually depress the bone marrow (1). Small transfusions may be given but there is certainly no evidence that this method of therapy is of specific value.

The use of adenine sulphate and nucleotide has been shown to be effective in more than 70 per cent of uncomplicated cases of agranulocytosis (5) (18). Although adenine sulphate has the disadvantage of being less soluble than nucleotide, it has been given at least 150 times with only two reports of minor constitutional reactions. Moreover, it is a simpler chemical product than nucleotide, and when effective, it produces some improvement in 24 hours and a distinct return towards normal in 48 hours. Salts of adenine, which are much more soluble, such as the lactate, the acetate, and the chloracetate of adenine, have been given to rabbits, and found to be non-toxic when administered either intravenously or intramuscularly. The clinical study of these more soluble adenine salts in agranulocytosis will soon be undertaken.

It must be emphasized that in a disease such as agranulocytosis spontaneous recovery is so common that any evidence such as has been reported in this study may be only circumstantial. Production of experimental agranulocytosis, more nearly simulating the disease than has been done in the past (19) (20), is essential before more definite proof of the value of therapeutic agents can be established.

\section{CONCLUSIONS}

1. Adenine sulphate therapy in $\mathbf{1 5}$ uncomplicated cases of agranulocytosis has been followed by recovery in 11 of the patients.

2. In severely complicated cases of agranulocytosis or in aleukemic leukemia and aplastic anemia, adenine sulphate has not been effective in the doses used in this study.

3. One gram of adenine sulphate boiled in 35 to $40 \mathrm{cc}$. of saline, given warm, intravenously three times a day, for at least three days for an adult, is nontoxic, and is suggested as the dose in treating agranulocytosis in adults.

\section{BIBLIOGRAPHY}

1. Reznikoff, P., J. Clin. Invest., 1930, ix, 381. Nucleotide Therapy in Agranulocytosis.

2. Ames, D., and Huntley, A. A., J. A. M. A., 1897, xxix, 472 . The Nature of the Leucocytosis Produced by Nucleinic Acid: A Preliminary Experimental Study.

3. Doan, C. A., Zerfas, L. G., Warren, S., and Ames, O., J. Exper. Med., 1928, xlvii, 403. A Study of the Mechanism of Nucleinate-induced Leucopenic and Leucocytic States, with Special Reference to the Relative Rôles of Liver, Spleen and Bone Marrow.

4. Reznikoff, P., J. Clin. Invest., 1928, vi, 16. Experimental Leukocytosis and Leukopenia.

5. Jackson, H., Jr., Parker, F., Jr., Taylor, F. H. L., and Rinehart, J., 1932, 47th Meeting of the Assoc. Am. Physicians, Atlantic City, May 4th. The Treatment of Malignant Leukopenia with Pentose Nucleotides. 
6. Jackson, H., Jr., Parker, F., Jr., Robb, G. P., and Curtis, H., Folia haemat., 1931, xliv, 30. Studies of Diseases of the Lymphoid and Myeloid Tissues. III. A Case of Acute Leukemia with a Five Months' Remission.

7. Rosenthal, N., Am. J. Clin. Path., 1931, i, 7. Hematological Aspects of Agranulocytosis and Other Diseases Accompanied by Extreme Leukopenia.

8. Roberts, S. R., and Kracke, R. R., Ann. Int. Med., 1931, v, 40. Agranulocytosis: Its Classification. Cases and Comments Illustrating the Granulopenic Trend from 8,000 Blood Counts in the South.

9. Brown, P. K., Am. Med., 1902, iii, 649. A Fatal Case of Acute Primary Infectious Pharyngitis with Extreme Leukopenia.

10. Schwarz, E., Mitt. d. Gesellsch. f. inn. Med. u. Kinderh., 1904, iii, 190. Ein Falle von extremer Leukopenie.

11. Türk, W., Wien. klin. Wchnschr., 1907, xx, 157. Septische Erkrankungen bei Verkümmerung des Granulozytensystems.

12. Schultz, W., Deutsche med. Wchnschr., 1922, xlviii, 1495. Ueber eigenartige Halserkrankungen, (a) Monocytenangina.

13. Hartwich, A., Ergebn. d. inn. Med. u. Kinderh., 1931, xli, 202. Das Krankheitsbild der Agranulocytose.

14. Friedemann, U., and Elkeles, A., Deutsche med. Wchnschr., 1930, lvi, 947. Die Roentgenbehandlung der Agranulozytose.

15. Taussig, A. E., and Schnoebelen, P. C., J. A. M. A., 1931, xcvii, 1757. Roentgen Treatment of Agranulocytosis.

16. Gager, L. T., and Speer, A. J., Am. J. Roentgenol., 1932, xxvii, 40. The Roentgen Treatment of Agranulocytosis.

17. Friedemann, U., Ztschr. f. klin. Med., 1928, cviii, 54. Angina Agranulocytotica.

18. Kracke, R. R., Personal Communication. Review of 350 Cases of Agranulocytosis.

19. Kracke, R. R., Am. J. Clin. Path., 1932, ii, 11. The Experimental Production of Agranulocytosis.

20. Fried, B. M., and Dameshek, W., Arch. Int. Med., 1932, xlix, 94. Experimental Agranulocytosis: Infection of Rabbits with Salmonella Suipestifer by Way of the Blood Stream. 